\title{
INCONTINENTIA PIGMENTI INVOLVING ONLY THE SKIN
}

MD. WAHIDUZZAMAN

\section{Introduction:}

Incontinentia pigmenti (IP) is an uncommon disorder which can affect the skin and other systems. . It is an $\mathrm{X}$-linked dominant genodermatosis mainly affecting the female baby with prenatal lethality in boys. ${ }^{1} \mathrm{It}$ was first reported by Garrod in $1906^{2}$ and further defined by Bloch and Sulzberger in 1926 and 1928. ${ }^{3}$ It can involve the skin only or in addition can affect the central nervous system, eyes and the teeth. The boys do not survive unless associated with Klinefelter syndrome (47, XXY). Morbidity and mortality are related to neurologic and ophthalmologic sequelae. Our presented case did not have any systemic involvement but only cutaneous symptoms.

\section{Case Report:}

We present a new born baby girl of day-1 who was referred from the nursery unit to our dermatology clinic for the evaluation of her skin in November 2007. The baby was born full term of a primiparous mother by normal spontaneous delivery. Since birth she presented with crops of erythematous vesicles on red bases on her both upper \& lower limbs distributed in a linear fashion bilaterally (Fig.-1 \& 2). There was no nail or mucosal involvement. The mother was healthy during her pregnancy and denied any vesicular or blistering disorder in recent days including genital

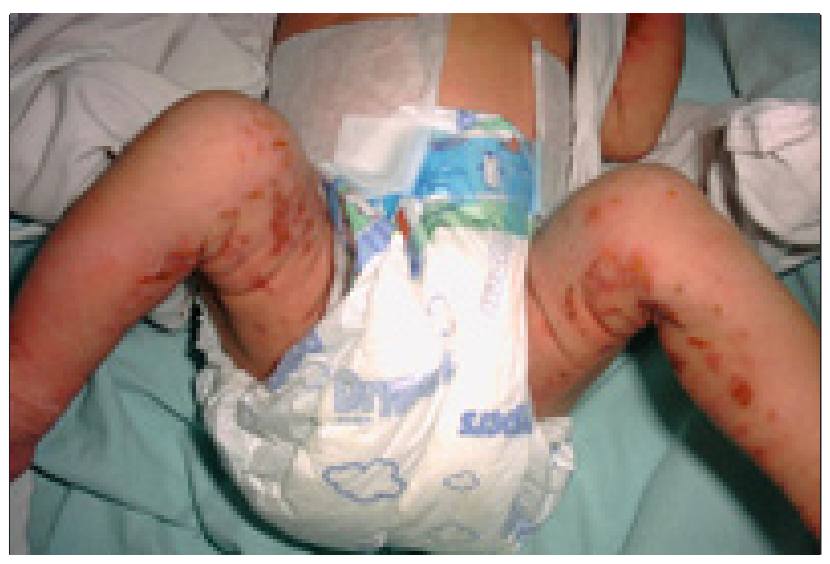

Fig.-1: Crops of vesicles in a linear distribution on both lower limbs on erythematous base. areas. She gives no history of abortion. Their marriage was non-consanguineous. The mother claims that she had similar problem when she was 4 months old. No other family member from both parents had any skin blisters in early childhood.

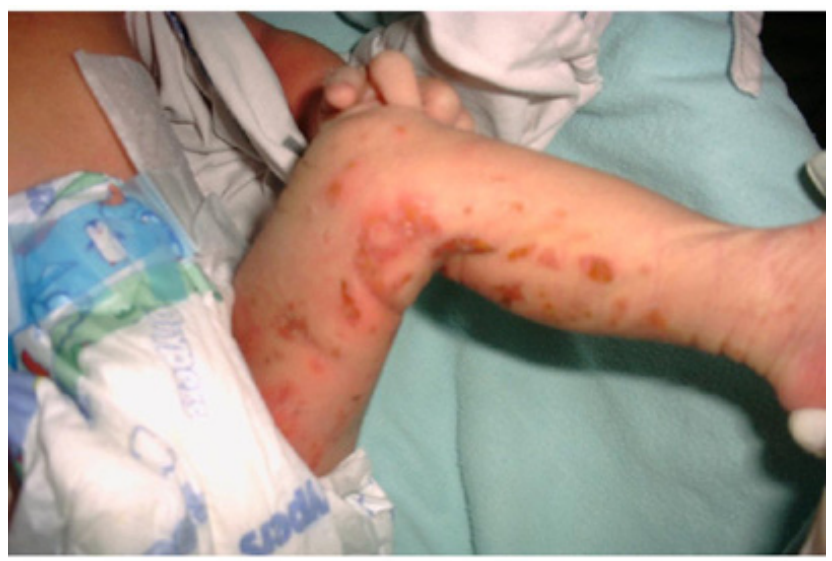

Fig.- 2: Visicles following the Blascho's line

On examination the baby was not febrile. Skin lesions showed linear streaks of pigmentation and vesicles on erythematous base along the line of Blaschko on the inner aspects of both upper and lower limb. Her systemic evaluation was normal including opthalmological and neurological examination. She did not develop any seizures during her stay in the hospital. A Tzanck smear and direct fluorescent antibody test for HSV was negative. Serum reactive plasma reagent was also negative. Swab from the blister fluids for culture and sensitivity did not show any growth after five days. Other than slight leukocytosis and mild eosinophilia all other work up for infectious diseases was normal. On examining the mother we did not find any hypopigmented or atrophic patches on the skin. A skin biopsy was not performed because the parents refused. The child was managed conservatively with daily normal saline soaks of the blisters and prophylactic antibiotics. The child was discharged from the hospital after 10 days of hospitalization.

Correspondence : Dr. M Wahiduzzaman, Medical Officer Specialist. Department of Dermatology, Sarawak General Hospital, Sarawak, Malaysia, E-mail: jhota68@hotmail.com 
On follow-up visit in three months and six months time the child was reviewed in one of our out-station clinic. Parents claim that by 2 weeks the blistering lesions healed completely with hyperpigmentation and there was no recurrence of blisters. On examination we noticed bluish, erythematous and pigmented macules and patches on the both upper and lower limbs (Fig.-3). They were distributed in a whorl and streaks pattern resembling Japanese character. During this time the baby did not develop any seizures. We also noticed her dental development which was normal and no alopecia. The parents were assured about the well being of the child with future followup.

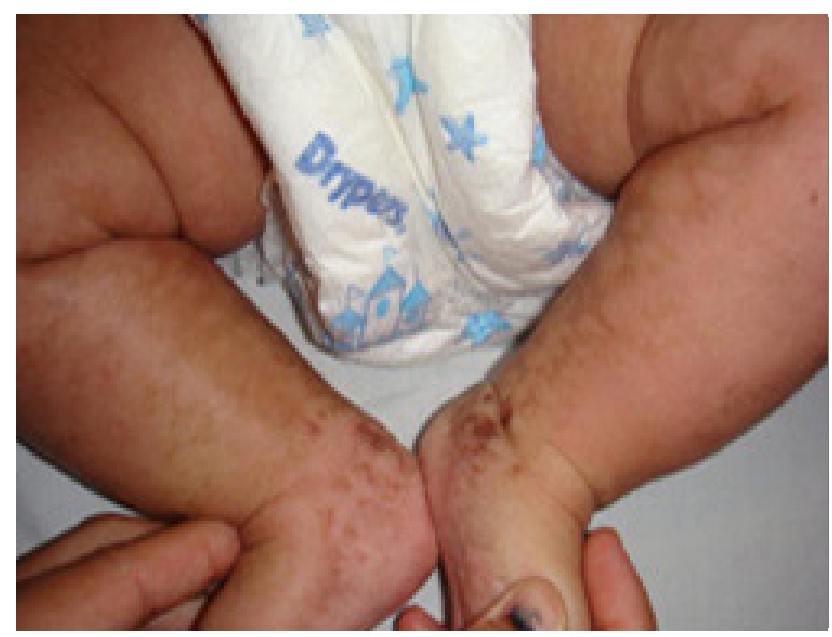

Fig.-3: Hyperpigmented lesion in a whorl and linear fashion.

\section{Discussions:}

Incontinentia pigmenti is a rare multisystem disorder and over the last century hundreds of cases have been described. Incontinentia pigmenti (IP) has derived its name from the common findings that there is incontinence of melanin from the basal cells in the superficial dermis as evidence by histological findings. ${ }^{2,4}$ In a recent discovery the genetic mutation for IP has been identified in the NEMO/IKK gene located on chromosome $\mathrm{Xq} 28$ that encodes a protein important in signaling pathways of apoptosis and inflammatory responses. ${ }^{5}$ The disease is embryologically derived from ectoderm and neuroectoderm. ${ }^{6}$

The natural history of IP typically evolves into four stages. Stage 1 (vesicobullous stage), Stage 2 (verrucous stage), Stage 3 (hyperpigmented stage),
Stage 4 (hypopigmented stage). All these four stages may not necessarily happen in a single patient and several stages may overlap. ${ }^{2}$ Our patient presented in stage 1 ; which resolved in 2 weeks time but did not notice the verrucous lesions as the patient was reviewed only at three months time when the hyperpigmented lesions has already evolved. But the parents claimed that after two weeks the lesions looked more thickened and prominent which resolved eventually with hyperpigmentation. We presume, that was her stage 2 or verrucous stage. As of eleven months of age we did not notice any systemic involvement in our patient. There are many reports of other systems involvement including cicatricial alopecia on the vertex ${ }^{7}$, nail dystrophy with onycholysis. ${ }^{7,8}$ Roughly $30 \%$ of patients are found to have cicatricial alopecia, which may be the only remaining sign in an adult women. ${ }^{9}$ Also reports of destructive encephalopathy ${ }^{10}$ and retinopathy ${ }^{11}$ are noted with bad prognosis. Male patient with IP are rare and more severely affected than the females and are mostly associated with Kleinfelter syndrome; in which the XXY genotype permits viability. Scheuerle $\mathrm{AE}^{12}$ in a report has reviewed 49 cases of male IP and found that five patients had Klinefelter syndrome (47, XXY) which is reported by other authors too. ${ }^{13}$

The skin manifestations of IP are considered diagnostic and stage 3 to be the hallmark of IP. ${ }^{14}$ Our case is diagnosed clinically on the findings of the major criteria outlined by Landy and Donnai as diagnostic criteria in $1993 .^{2}$ Our case fulfills the two major criteria of diagnosis. Moreover the finding of hypereosinophilia; which is also described by Carney $\mathrm{RG}^{9}$ as preliminary inflammatory phase is most of the time, is associated with peripheral blood leukocytosis with eosinophilia supports our diagnosis further. We were unable to do a skin biopsy as the parents refused. Our patient is yet to develop the stage 4 or hypopigmented stage where hypopigmented or atrophic streaks could appear any time between the late infancy and adolescent years and may last for a lifetime ${ }^{6}$ IP may mimic herpes simplex infection in a new born and may look like traumatic injury and misdiagnosed to be as child abuse and congenital herpes simplex infection. ${ }^{14,15,16}$ So careful examination of a baby who is born with vesicular lesion or develop later is of utmost importance. The case would be further followed up to look for any skin and systemic changes. 


\section{References:}

1. Singh R, K Devender. Incontinentia pigmenti. Indian J Dermatol Venereol 1970; 36:53-56.

2. Landy SJ, Donnai D. Incontinentia pigmenti (BlochSulzberger syndrome). J Med Genet 1993; 30:53 59.

3. Shah KN, Tsuji T, Incontinentia Pigmenti.e Medicine 2007.

4. Sulzberger MB. Arch Dermatol Syphilol 1938; 38:57 -69 .

5. Berlin AL, Paller AS, Chan LS. Incontinentia pigmenti: a review and update on the molecular basis of pathophysiology. J Am Acad Dermatol 2002; 47:169 -187.

6. Cohen BA. Incontinentia pigmenti. Neurol Clin 1987; 5:361 -377.

7. Lahari KD. Incontinentia pigment. Br J Dermatol 1955; 67:310-312.

8. Aggarwal K, Jain VK, Dayal S. Incontinentia Pigmeni with nail dystrophy. Indian J Dermatol Venereol Leprol 2003; 69:3-4.

9. Carney RG Incontinentia pigmenti: a world statistical analysis. Arch Dermatol 1976; 112:535542 .
10. Yang JH, Ma SY, Tsai CH.Destructive encephalopathy in incontinentia pigmenti: a case report.J Dermatol 1995 ; 22(5):340-3.

11. Cates C.A.; Dandekar S.S.; Flanagan D.W.; Moore A.T. Retinopathy of incontinentia pigmenti: a case report with thirteen years follow-up. Ophthalmic Genetics 2003; 24(4) :247-252.

12. Scheuerle AE. Male cases of incontinentia pigmenti: case report and review. Am J Med Genet 1998; 77(3):201-18.

13. Franco, J. Goldstein, N. Prose et al. Incontinentia pigmenti in a boy with XXY mosaicism detected by fluorescence in situ hybridization. Journal of the American Academy of Dermatology ;55(1): 136 138.

14. Ciarallo L, Paller AS. Two cases of incontinentia pigmenti simulating child abuse Pediatrics 1997 ; 100(4):E6.

15. Faloyin M, Levitt J, Bercowitz E et al. All that is vesicular is not herpes: incontinentia pigmenti masquerading as herpes simplex virus in a newborn. Pediatrics 2004 ; 114(2):e270-2.

16. Okan F, Yapici Z, Bulbul A. Incontinentia pigmenti mimicking a herpes simplex virus infection in the newborn. Childs Nerv Syst 2008 ; 24(1):149-51. 